\title{
Emerging options for the management of scorpion stings
}

\author{
This article was published in the following Dove Press journal: \\ Drug Design, Development and Therapy \\ 3 July 2012 \\ Number of times this article has been viewed
}

\author{
Jean-Philippe Chippaux \\ UMR 216 (Institute of Research for \\ Development and University Paris \\ Descartes, Sorbonne Paris Cité), \\ Cotonou, Bénin, France
}

\begin{abstract}
Scorpion stings are common in many tropical countries. Although most scorpion stings cause only localized pain without life-threatening envenoming, about one third of stings cause systemic envenoming which can result in death. Children are particularly sensitive to scorpion envenoming. The severity of scorpion stings is related to the presence of neurotoxins in the venom that cause a sudden release of neurotransmitters from the autonomic nervous system, predominantly sympathetic. There is also a strong inflammatory response that worsens symptoms, including those of a respiratory nature. Several vital functions may be directly affected, including the cardiovascular, respiratory, and neuromuscular systems. Hypertension is constant at the beginning of systemic envenoming and sometimes has a severe cardiac and respiratory impact. Although controversial, immunotherapy is the only etiological treatment. Administered early, it prevents many complications and improves the outcome. New antivenoms are highly purified immunoglobulin fragments, the efficacy and safety of which are excellent. As a consequence, adverse reactions to antivenoms are now very rare and usually mild, which should limit any reluctance regarding their routine use. Symptomatic treatment is still necessary to support immunotherapy, especially in cases of delayed arrival at hospital. A combination of both approaches should be considered, based on local resources and constraints.
\end{abstract}

Keywords: scorpion, envenoming, treatment, antivenom

\section{Introduction}

Scorpion stings are common emergency events in many parts of the world. ${ }^{1}$ The estimated annual global incidence, based on national health data, is about 1.5 million envenomings involving 2600 deaths (Figure 1). Although the incidence of scorpion stings is higher in adults, the severity of envenoming is significantly greater in children, in whom the case fatality rate is up to ten times higher than in adults. ${ }^{1-6}$ However, the incidence of scorpion stings is under-researched, although mortality appears to have decreased in most countries as a result of appropriate management. ${ }^{1,2,5}$ Indeed, victims of scorpion stings are going more readily and rapidly to hospital, where the appropriate care can be given. This is a consequence of greater consideration given to envenoming by health authorities. ${ }^{2,5}$ The epidemiology of envenoming, including the incidence and circumstances of scorpion stings, has promoted better allocation of resources, appropriate training of health personnel, and implementation of management strategies for accidents. ${ }^{7}$

The improvement in management of scorpion stings has revived the controversy over their treatment. ${ }^{1}$ This controversy, ie, passive immunotherapy versus symptomatic treatment, arose mostly in Africa and Asia, primarily because medical intensive care services 


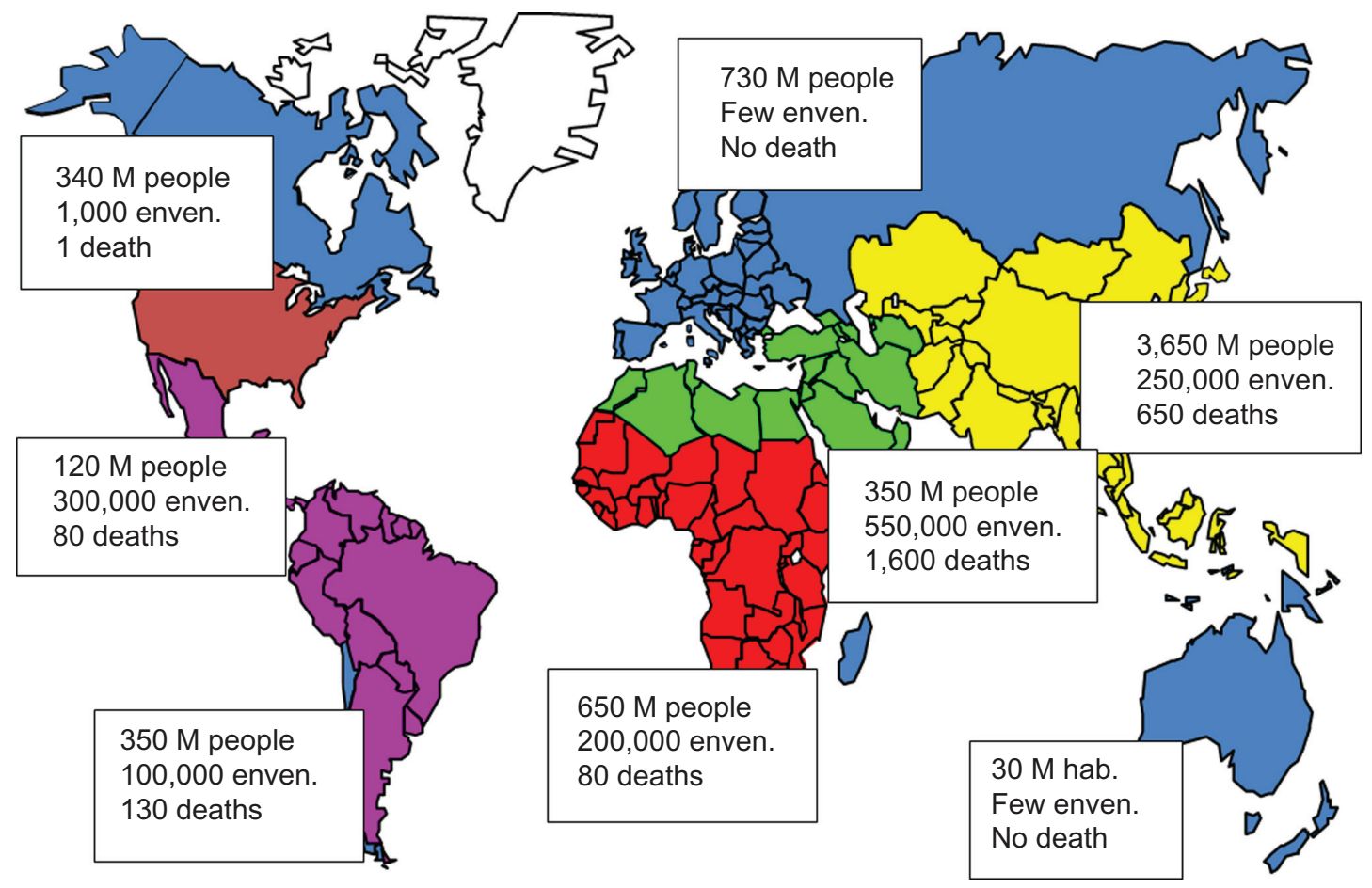

Figure I World incidence and mortality following scorpion stings Abbreviations: enven, envenomings; $M$, million.

were developed and spread to provincial hospitals in many countries affected by scorpionism. Thus, improvements in symptomatic treatment and its accessibility led to consideration of the latter as an acceptable emergent treatment alternative. Medical intensive care remains the exclusive domain of a minority of specialists. Use of antivenoms requires that they are of the highest quality, both in terms of efficacy and safety, and for optimal efficacy, that they are administered early to remove the venom as soon as possible. The newer antivenoms are composed of highly purified fragments of immunoglobulin (IgG), making them safer without altering their efficacy and facilitating their use, even in peripheral facilities that do not have intensive care units.

The objective of this review is to update knowledge on the management of scorpion stings and treatment of scorpion envenomings, to discuss the advantages and limitations of early immunotherapy versus medical resuscitation, and to offer a standardized management plan based on a combination of both strategies.

\section{Composition of scorpion venom}

Scorpions are a very homogeneous group of arthropods comprising about 1500 species, of which about 30, all belonging to the family Buthidae, are potentially dangerous to humans. They are shy creatures, active at night during the hot season, but often live in houses or near inhabited areas, which explains the high incidence of scorpion stings involving children in many parts of the world.

The venomous apparatus of the scorpion consists of a venom vesicle comprising a pair of joined glands in the telson, ie, the last segment of the post-abdomen. This venom vesicle is surrounded by a striated muscular layer facilitating and regulating the ejection of venom. This ability partly explains the variation in intensity of symptoms and the possibility of "dry" stings, ie, without inoculation of venom.

Scorpion venom is composed of toxins and enzymes with neurological tropism acting on ion channels of excitable cells. Classification of toxins ${ }^{8}$ is based on four distinct criteria: the involved ion channel (in particular those for sodium, potassium, chlorine and calcium); the specific receptor to which the toxin binds within the ion channel; the three-dimensional structure of the toxin; and the type of response induced (activation/inactivation of the receptor). The venom of the same scorpion can have multiple toxins that may interact with each other, modulating the response of the ion channels involved and leading to complex and rapidly progressive symptoms. ${ }^{9}$

Toxins binding to the sodium channel are most important, at least with regard to mammals, particularly humans. ${ }^{9-11}$ Among the categories currently described, two main types can be distinguished, ie, toxins- $\alpha$ and toxins- $\beta$. Toxins- $\alpha$ (known as "potential-dependent") present in the venom 
of paleotropical scorpions have a binding affinity for their receptor proportional to the intensity of the polarization of the membrane. Toxins- $\alpha$ inactivate the closing potential of the sodium channel, without modifying the opening potential, so act only when the channel is opened. The main consequence is strong depolarization of the membrane, followed by a drop in excitability. ${ }^{12}$ At high doses, they prolong the action potential of excitable cells and induce paralysis and cardiac arrhythmia. ${ }^{9}$ Toxins- $\beta$, isolated from the venom of American scorpions, act on another site of the sodium channel activated at a lower action potential and independently of the membrane potential, ${ }^{13}$ resulting in myoclonic or spastic muscular responses. However, some South American scorpions, such as Tityus serrulatus, have a toxin (also called $\gamma$-toxin) which has a combined effect, ie, it blocks the opening of the channel but also blocks its closure when the channel is already open. ${ }^{14}$

Other toxins affecting membrane ion channels, including those for potassium, ${ }^{8,15}$ are of great interest in neurobiology and pharmacology, but seem to have a subsidiary role in human envenoming. However, all these toxins can have a synergistic action on clinical symptoms, resulting in paradoxical syndromes or severe complications. Consequently, a toxin which may have individually mild clinical effects can become toxic, or increase the toxicity of other toxins, when they are associated.

Very often, studies pit cardiovascular complications against respiratory failure while they both could be the consequence of a) a difference in the composition of the venom, b) a delayed consultation, or even c) an inappropriate initial treatment.

\section{Clinical manifestations of scorpion envenoming}

The first symptom of scorpion envenoming is localized pain, which reflects the penetration of the venom and is a valuable warning signal, especially in children. Pain is present in more than $95 \%$ of cases of envenoming and may be associated with edema and erythema (in $20 \%$ of cases), more rarely small blisters.

The systemic manifestations of scorpion envenoming occur in less than a third of victims of scorpion stings. These manifestations result from the release of neurotransmitters in response to the actions of the toxin on sodium channels. These neurotransmitters will cause a strong and complex response taking the form, simultaneously or sequentially, of an adrenergic or cholinergic syndrome associated, especially in the case of Tityus and paleotropical scorpion envenoming, with an inflammatory response (see the comprehensive reviews by Freire-Maia et al and Ismail). ${ }^{16-18}$ Symptoms develop rapidly, within a few hours, leading to a range of clinical pictures according to the species of scorpion. They are associated with biological disorders, the most frequent of which are leukocytosis, hyperglycemia, and lactic acidosis. There is a significant increase in biomarkers for muscle necrosis, particularly cardiac (aspartate transaminase, creatine phosphokinase, and troponin I), hepatic (alanine transaminase, gamma glutamyl transferase, alkaline phosphatase) and pancreatic (lipases, amylases), of which the latter is likely to be more frequent after envenoming by the South American Tityus. Electrolytes are disturbed (hyponatremia, hypocalcemia, hyperkalemia), especially in severe envenoming, and this heralds a poor prognosis. Arterial oxygen saturation $\left(\mathrm{SaO}_{2}\right)$ is likely to be less than $90 \%$.

Overstimulation of the sympathetic system increases blood levels of catecholamines, resulting in a characteristic "adrenergic (autonomic) storm" which consists of cardiac (tachycardia, peripheral vasoconstriction, hypertension, diaphoresis), metabolic (hyperthermia, hyperglycemia), urogenital (bladder dilatation, urinary retention, ejaculation in males), respiratory (bronchial dilation, tachypnea), and neuromuscular (mydriasis, tremor, agitation, convulsions) complications.

In contrast, a cholinergic (or muscarinic) syndrome can occur involving the parasympathetic nervous system. This combines a hypersecretion syndrome (salivation, sweating, vomiting, urinary incontinence, bronchial hypersecretion, and diarrhea), abdominal pain, miosis, bronchospasm, bradycardia with hypotension and, in the male, priapism. This syndrome seems to be rarer, delayed, or masked by the adrenergic storm.

In addition, the release of inflammatory substances or vasodilators (kinins, prostaglandins) reinforces and exacerbates some symptoms (fever, dyspnea, visceral infarction) which can become dominant. Therefore, each vital organ can be affected and endangered by envenoming, treatment of which becomes a priority.

The early and persistent cardiac defects observed in scorpion envenoming are caused by release of catecholamines. The first symptoms, ie, tachycardia, arrhythmia, and hypertension, rapidly impair cardiac function. Peripheral vasoconstriction, probably reinforced by the action of kinins, accentuates cardiac ischemia, as evidenced by changes on electrocardiography (in particular QT prolongation, increased or inverted $\mathrm{T}$ waves, and ST-segment abnormalities), and 
echocardiography and scintigraphy confirm decreased myocardial perfusion. ${ }^{3,19}$ These changes can lead to myocardial necrosis inducing heart failure and death. ${ }^{20,21}$ More generally, the systolic ejection fraction is significantly lowered, explaining the respiratory effects of acute pulmonary edema, acute heart failure, and cardiogenic shock. ${ }^{16-18,22}$ This evolution is the consequence of a succession of events related to the adrenergic storm and exacerbation of the inflammatory response, as suggested by high plasma concentrations of kinins, prostaglandins, and inflammatory cytokines, including interleukins 1 and 6, interferon gamma, and tumor necrosis factor alpha. ${ }^{23-30}$

Similar mechanisms (vascular constriction, increased peripheral vascular resistance, local edema) may explain some visceral impairments, including those affecting the kidney, ${ }^{31,32}$ mesentery, ${ }^{31}$ and brain. ${ }^{33-35}$ Finally, blood electrolyte disturbances are reflected clinically by cardiac, renal, and metabolic disorders. Various electrolytic disturbances due to catecholamine release (hyperkalemia, hyponatremia, hypocalcemia), hyperglycemia, acidosis, or even myocardial necrosis may accentuate these complications. ${ }^{18}$

The neuromuscular hyperexcitability entails abnormal movements, twitching, tremors, convulsions, and cramps affecting all the skeletal muscles, but predominantly the cranial nerves. Rapid aberrant eye movements are likely to be more frequent during envenoming by Centruroides, found in North and Central America. Movements are bilateral and symmetrical, horizontal or rotary, suggesting a peripheral origin, which some authors have attributed to cerebral edema, potentially due to vasoconstriction of brain capillaries, including those in the thalamus. ${ }^{34}$ The convulsive forms sometimes attributed to hyperthermia and dehydration in very young children could be of the same origin. An adrenergic etiology remains the most probable, perhaps accentuated by individual susceptibility or age.

The severity of scorpion envenoming may be evaluated by a scoring system. Several scales have been proposed, and an attempt at consensus was recently published. ${ }^{36}$ Three grades are generally used, ie, grade I for local events, grade II for mild systemic symptoms, and grade III for lifethreatening envenoming (Table 1). The first group represents about $70 \%$ of patients, the second $20 \%$, and the third less than $10 \%$.

\section{Management of scorpion stings}

Scorpion stings usually occur at night, at the victim's home, in suburbs or center of small towns, and in rural areas. Arrival at the health center may be delayed by up to $1-2$ hours after the sting because of an initial preference for traditional medicine, the health center being remote, or the patient having been referred from a health center lacking appropriate health care resources. ${ }^{1,4}$ First aid is usually administered by health staff with limited appropriate training.

\section{Adjuvant and symptomatic treatment}

Use of analgesics, even if they are not the most essential drugs in envenoming, is still important because pain is frequent and intense. It can be useful to administer analgesics with an

Table I Clinical score of scorpion envenoming and corresponding treatment

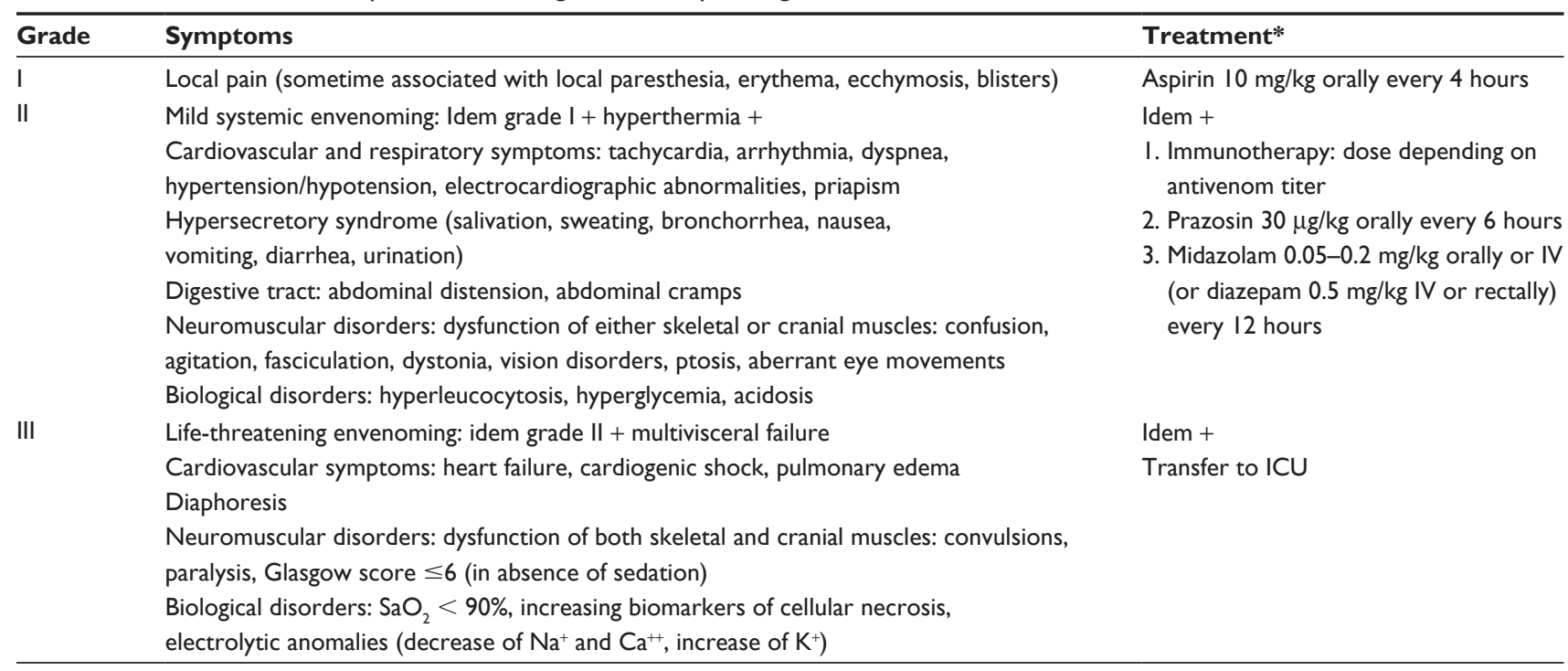

Note: *See indications, precautions, and comments in the text.

Abbreviations: ECG, electrocardiogram; ICU, intensive care unit; IV, intravenously. 
anti-inflammatory action, such as salicylates, mindful that use of salicylates could trigger Lyell's syndrome or Reye's syndrome, the latter occurring mostly in children during viral infections treated by salicylates. ${ }^{37}$ The incidence of Reye's syndrome, the symptoms of which can be confused with worsening of envenoming, is low at about 0.8 cases per million children, ${ }^{38}$ but is often fatal. Therefore, it is necessary to assess the risk/benefit ratio, taking into account that $15 \%-20 \%$ of scorpion stings can show severe progression and $0.5 \%-1 \%$ of these stings can be fatal in children, and consider other treatments that could also be beneficial. Some authors recommend local anesthesia with $1 \%$ lignocaine..$^{39}$ In contrast, morphine or its derivatives or analogs (codeine, tramadol), although very effective, ${ }^{40}$ should be avoided because the opioid receptor agonists inhibit noradrenaline reuptake, which may potentiate their effects; these agents also cause respiratory depression, worsening the patient's respiratory condition.

Many drugs aiming at cardiac treatment have been proposed to treat the hypertension, arrhythmia, heart failure, and pulmonary edema associated with scorpion envenoming. However, it should be borne in mind that the main origin of these symptoms is the increase in vascular resistance caused by peripheral vasoconstriction as a result of the action of catecholamines.

Among the vasodilators, the $\alpha_{1}$-adrenergic blockers, in particular prazosin, are of interest. Prazosin is recommended for the treatment of scorpion envenoming, especially in India. ${ }^{41}$ This drug is easy to use and has no major contraindications. Prazosin is more effective than nifepidine which blocks calcium ion influx of smooth muscle cells in the arterioles and inhibits their contraction. ${ }^{42}$ Hydralazine inhibits release of calcium ions in the smooth muscle of the vascular wall. Although effective, hydralazine has several disadvantages, including sympathetic stimulation which increases heart rate, with a risk of myocardial infarction, and an increase in plasma renin, leading to urinary retention requiring treatment with a $\beta_{2}$-adrenergic blocker and diuretic. Further, hydralazine administered parenterally produces a prolonged hypotensive response which is difficult to control. ${ }^{18}$ Captopril, a drug that inhibits the conversion of angiotensin has also been suggested. ${ }^{43}$ However, captopril inhibits degradation of bradykinin, which plays an important role in the development of acute pulmonary edema. ${ }^{18}$ Clonidine is an agonist of $\alpha_{2}$-adrenergic receptors that inhibits sympathetic activity. It causes a decrease in heart rate and peripheral blood pressure. Clonidine could be a useful drug, but to the author's knowledge, has never been evaluated in the treatment of scorpion envenoming.
When heart failure is confirmed, many practitioners use dobutamine alone or in combination with diuretics or antiarrhythmics. Gupta et $\mathrm{al}^{44}$ showed that prazosin is slightly better than dobutamine in terms of faster recovery, and also because it is easier to administer. However, this could be due to the particular circumstances or scorpion species involved, given that heart failure is a late complication of scorpion envenoming.

Neuromuscular disorders are most often treated with drugs activating gamma butyric acid (GABA) receptors that inhibit the excitability of postsynaptic neurons. Benzodiazepines have the advantage over other anticonvulsants, such as barbiturates (eg, phenobarbitone) because of their rapid distribution in the organism and short half-life. Barbiturates also have a depressive effect on respiration. Midazolam is the most widely used, particularly in North America. ${ }^{45,46}$ Elsewhere, particularly in Africa and the Middle East, diazepam is used extensively. ${ }^{39}$ In addition, benzodiazepines are beneficial in the treatment of hypertension and could be the initial drug of choice in the treatment of scorpion envenoming.

In general, antiparasympathetic drugs, such as atropine, are not recommended routinely in the treatment of scorpion envenoming. These cause blockage of sweating, which is essential for temperature regulation, especially in children, and potentiate the adrenergic effects of scorpion venom, increasing hypertension and ischemic complications. ${ }^{16,18,47,48}$ However, these drugs can be useful in cases of severe bradycardia or complete atrioventricular block, which are sometimes observed.

Anti-inflammatory drugs have never been subjected to formal clinical studies on the treatment of scorpion envenoming. However, there is no doubt that their therapeutic value is significant, even taking into account the risk of side effects. As we have seen, experimental studies have shown that many biological markers of inflammation are involved in scorpion envenoming, and have been confirmed in the clinic. So there are new issues for clinical research. It is indeed easy to treat pain with analgesics having an anti-inflammatory effect, such as salicylates.

The choice between the various available drugs is difficult because the indications and dosages differ depending on: venom composition, which varies according to species and even individuals; the amount of venom injected; complications related to progression of envenoming, including delay in consultation; side effects of the drug; and modalities of drug administration, especially in peripheral health centers where there is often no doctor present. 


\section{Passive immunotherapy}

Passive immunotherapy, discovered in 1894, is the only etiological treatment of snakebite or scorpion envenoming. ${ }^{49}$ Immunotherapy is based on administration of antibodies produced by an animal that has been previously hyperimmunized against the venom of the corresponding or a very close species. Improvement of antivenomous sera is obtained by first separating the antibodies from other plasma components, followed by enzymatic digestion of $\mathrm{IgG}$, then purification of the final product. As a consequence, efficacy and safety are significantly increased. Most of the antivenoms currently manufactured are purified fragments of IgG $\left.\left[\mathrm{F}(\mathrm{ab})_{2}\right)_{2}\right]$, which reduces potential adverse effects. However, poorly refined antivenoms may induce severe adverse reactions, such as shock or anaphylaxis, which necessitate rapid administration of adrenaline.

Antivenom should be administered as earlier as possible, and intravenously for better diffusion and to facilitate complexation with the venom. The IgG antibodies and $\left.\mathrm{F}(\mathrm{ab})_{2}\right)_{2}$ fragments do not diffuse out of the blood compartment in which they bind to the venom. Elimination of the antigenantibody complex formed by the venom and $F\left(a b^{\prime}\right)_{2}$ attracts the venom from the tissue compartment to the blood, where the venom is complexed with $\left.\mathrm{F}(\mathrm{ab})_{2}\right)_{2}$. Even if the venom is not immediately neutralized by antibodies, its removal causes rapid regression of symptoms. This has been confirmed both experimentally and clinically. ${ }^{46,50-52}$

The dosage is based on symptoms, time between the sting and initiation of treatment, clinical progression, antivenom titer, and the medical environment, including the capacity to administer adjuvant therapy. Dosage is probably one of the main aspects that remains to be documented.

Antivenoms are particularly controversial in Africa and India with regard to their efficacy and usefulness in the treatment of scorpion envenoming for several reasons. ${ }^{4,6,53,54}$ First, there is a fear of side effects which dates back to the time when poorly refined whole $\mathrm{IgG}$ were used. The case fatality rate attributable to scorpion stings, albeit relatively low even at that time $(1 \%-2 \%)$, was offset by the high incidence of side effects (occurring in at least $50 \%$ of patients treated with antivenom), some of which are life-threatening. This is no longer the situation with the advent of $\mathrm{F}\left(\mathrm{ab}^{\prime}\right)_{2}$, the side effects of which are rare $(<5 \%)$ and generally mild. ${ }^{1,49}$ Second, there has been concern about incorrect administration of antivenom, either by an inappropriate route (other than intravenous) or at insufficient doses. Indeed, most treatments, including those used in clinical trials, used antivenoms with a neutralizing titer of about $10 \mathrm{ED}_{50}$ (ie, $1 \mathrm{~mL}$ of antivenom neutralized an amount of venom corresponding to $10 \mathrm{LD}_{50}$ ), while the current antivenoms show a neutralizing titer of more than $50 \mathrm{ED}_{50}$ (Table 2), ie, are 3-5 times more effective. Finally, clinical trials performed in order to confirm the efficacy of antivenoms have been very few in number and often biased. ${ }^{55}$ However, a randomized placebo-controlled, blinded clinical trial carried out by Boyer et $\mathrm{al}^{46}$ showed that: antivenom removed the venom from the plasma compartment in less than one hour (versus more than 4 hours on average for the placebo group); the benzodiazepine dose needed was significantly lower in the group treated by antivenom; and cure was achieved in less than 4 hours in all patients treated with antivenom (versus only $15 \%$ in the control group).

\section{Practical management of patients with scorpion sting}

Immunotherapy, provided that the antivenom is appropriate, of high-quality, and accessible, is both curative because it eliminates the venom and preventive because it reduces the risk of subsequent complications. For these reasons, it is essential to administer antivenom as soon as possible after the sting. Moreover, this should be made known to the public and implies organizational logistics (distribution and stock management in peripheral health centers, health staff training). The main limitation to the use of antivenoms is their accessibility, either because of supply problems or cost, which is sometimes quite high. Table 2 provides a nonexhaustive list of currently marketed antivenoms.

Symptomatic treatment is needed in the event of progression of symptoms and complications of envenoming that may appear before administration of antivenom, which is frequently due to delayed consultation. The two approaches are complementary. However, combination of both is highly dependent on local conditions, health center resources, and the level of training of health personnel. For example, use of some drugs is not desirable in remote health centers, which often lack doctors, while others can be easily administered. Finally, we need to take into account the severity of envenoming, which is greatly influenced by delay in consultation. Fortunately, assessment of severity using a scoring system can largely resolve this problem, enabling treatment to fit the grade of envenoming (Table 1).

Symptomatic treatment only is recommended in grade I (local) envenoming, for which immunotherapy is not helpful and too expensive. Salicylates are recommended at this stage (aspirin $10 \mathrm{mg} / \mathrm{kg}$ orally every 4 hours for children and adults), even if they are not in use in some countries, like the United States. Systemic envenoming (grade II and III) 
Table 2 List of the main marketed scorpion antivenoms

\begin{tabular}{|c|c|c|c|}
\hline Name/website* & Manufacturer & Formulation and titer & Neutralized species \\
\hline $\begin{array}{l}\text { Polyvalent scorpion antivenom } \\
\text { http://www.antivenom-center.com/ }\end{array}$ & $\begin{array}{l}\text { National Antivenom and Vaccine } \\
\text { Production Center, Saudi Arabia }\end{array}$ & $\begin{array}{l}\text { Horse purified } \mathrm{F}\left(\mathrm{ab}^{\prime}\right)_{2} \\
\text { Vial I } \mathrm{mL} \text { (liquid) } \\
\text { Unspecified titer }\end{array}$ & $\begin{array}{l}\text { Leiurus quinquestriatus } \\
\text { Androctonus } \\
\text { crassicauda }\end{array}$ \\
\hline $\begin{array}{l}\text { Sérum antiscorpionique } \\
\text { http://www.pasteur.tn/ }\end{array}$ & Institut Pasteur de Tunis, Tunisia & $\begin{array}{l}\text { Horse purified } \mathrm{F}\left(\mathrm{ab} \mathrm{b}^{\prime}\right)_{2} \\
\text { Unspecified formulation and titer }\end{array}$ & $\begin{array}{l}\text { Androctonus australis } \\
\text { Buthus occitanus }\end{array}$ \\
\hline $\begin{array}{l}\text { Sérum antiscorpionique } \\
\text { http://www.pasteur.dz/ }\end{array}$ & Institut Pasteur d'Algérie, Algeria & $\begin{array}{l}\text { Horse purified } \mathrm{F}\left(\mathrm{ab}{ }^{\prime}\right)_{2} \\
\text { Vial } 10 \mathrm{~mL} \text { (liquid) } \\
\text { Unspecified titer }\end{array}$ & Androctonus australis \\
\hline $\begin{array}{l}\text { Scorpifav }^{\circledR} \\
\text { www.sanofipasteur.com/ }\end{array}$ & Sanofi Pasteur, France & $\begin{array}{l}\text { Horse purified } \mathrm{F}(\mathrm{ab})_{2} \\
\text { Vial I } \mathrm{mL} \text { (liquid) } \\
\text { Neutralize } 50 \mathrm{DL}_{50} / \mathrm{mL}\end{array}$ & $\begin{array}{l}\text { Leiurus quinquestriatus } \\
\text { Androctonus australis } \\
\text { Buthus occitanus }\end{array}$ \\
\hline $\begin{array}{l}\text { Soro antiescorpiônico } \\
\text { http://www.butantan.gov.br/ }\end{array}$ & Instituto Butantan-Brasil & $\begin{array}{l}\text { Horse purified } \mathrm{F}\left(\mathrm{ab}{ }^{\prime}\right)_{2} \\
\text { Vial } 5 \mathrm{~mL} \text { (liquid) } \\
\text { Neutralize } 7.5 \text { minimal lethal doses }\end{array}$ & Tityus serrulatus \\
\hline $\begin{array}{l}\text { Soro antiescorpiônico } \\
\text { http://www.ivb.rj.gov.br/ }\end{array}$ & Instituto Vital Brazil, Brasil & $\begin{array}{l}\text { Horse purified } \mathrm{F}\left(\mathrm{ab} \mathrm{b}_{2}\right. \\
\text { Unspecified formulation and titer }\end{array}$ & Tityus serrulatus \\
\hline $\begin{array}{l}\text { Suero antiescorpiónico } \\
\text { http://caibco.ucv.ve/ }\end{array}$ & $\begin{array}{l}\text { Centro de Biotecnología, } \\
\text { Venezuela }\end{array}$ & $\begin{array}{l}\left.\text { Horse purified } \mathrm{F}(\mathrm{ab})_{2}\right)_{2} \text { Vial } 5 \mathrm{~mL} \text { (liquid) } \\
\text { Neutralize } 0.2 \mathrm{mg} / \mathrm{mL}\end{array}$ & Tityus discrepans \\
\hline $\begin{array}{l}\text { Antiveneno escorpión } \\
\text { http://www.anlis.gov.ar/ }\end{array}$ & $\begin{array}{l}\text { ANLIS Dr Carlos Malbrán, } \\
\text { Argentina }\end{array}$ & $\begin{array}{l}\left.\text { Horse purified } \mathrm{F}(\mathrm{ab})_{2}\right)_{2} \\
\text { Vial } 2 \mathrm{~mL} \text { (liquid) } \\
\text { Neutralize } 200 \mathrm{LD}_{50} / \mathrm{mL}\end{array}$ & Tityus trivittatus \\
\hline $\begin{array}{l}\text { Alacramyn }^{\circledast} \text { (Mexico), } \\
\text { Anascorp }^{\circledR} \text { (US) } \\
\text { http://www.bioclon.com.mx/ }\end{array}$ & Instituto Bioclon, Mexico & $\begin{array}{l}\text { Horse purified } \mathrm{F}(\mathrm{ab})_{2} \\
\text { Vial } 5 \mathrm{~mL} \text { (lyophilized) } \\
\text { Neutralize } 30 \mathrm{LD}_{50} / \mathrm{mL}\end{array}$ & $\begin{array}{l}\text { Centruroides limpidus } \\
\text { Centruroides noxius } \\
\text { Centruroides suffusus } \\
\text { Centruroides meisei }\end{array}$ \\
\hline $\begin{array}{l}\text { Faboterápico, polivalente alacrán } \\
\text { http://www.birmex.gob.mx/ }\end{array}$ & Birmex, Mexico & $\begin{array}{l}\text { Horse purified } \mathrm{F}\left(\mathrm{ab} \mathrm{b}^{\prime}\right)_{2} \\
\text { Vial } 5 \mathrm{~mL} \text { (liquid) } \\
\text { Unspecified titer }\end{array}$ & $\begin{array}{l}\text { Centruroides limpidus } \\
\text { Centruroides noxius } \\
\text { Centruroides suffusus }\end{array}$ \\
\hline $\begin{array}{l}\text { SAVP scorpion antivenom } \\
\text { http://www.savp.co.za/ }\end{array}$ & $\begin{array}{l}\text { South African Vaccine } \\
\text { Producers, South Africa }\end{array}$ & $\begin{array}{l}\text { Horse purified } \mathrm{F}\left(\mathrm{ab}{ }^{\prime}\right)_{2} \\
\text { Vial } 5 \mathrm{~mL} \text { (liquid) } \\
\text { Unspecified titer }\end{array}$ & $\begin{array}{l}\text { Parabuthus } \\
\text { transvaalicus }\end{array}$ \\
\hline $\begin{array}{l}\text { Polyvalent scorpion serum } \\
\text { http://www.sigma.ir/ }\end{array}$ & $\begin{array}{l}\text { Razi Serum and Vaccine } \\
\text { Research Institute, Iran }\end{array}$ & Unspecified & Unspecified \\
\hline $\begin{array}{l}\text { Purified polyvalent antiscorpion } \\
\text { serum } \\
\text { http://www.vacsera.com/ }\end{array}$ & Vacsera, Egypt & $\begin{array}{l}\text { Horse purified } \mathrm{F}\left(\mathrm{ab} \mathrm{b}^{\prime}\right)_{2} \\
\text { Vial I mL (lyophilized) } \\
\text { Unspecified titer }\end{array}$ & Unspecified \\
\hline $\begin{array}{l}\text { Antiscorpion venom serum } \\
\text { http://www.vaccinehaffkine.com/ }\end{array}$ & $\begin{array}{l}\text { Haffkine Biopharmaceutical } \\
\text { Corporation, India }\end{array}$ & $\begin{array}{l}\text { Horse purified } \mathrm{F}\left(\mathrm{ab}{ }^{\prime}\right)_{2} \\
\text { Vial } 10 \mathrm{~mL} \text { (lyophilized) } \\
\text { Neutralize } 25 \mathrm{LD}_{50} / \mathrm{mL}\end{array}$ & Mesobuthus tamulus \\
\hline $\begin{array}{l}\text { Androctonus crassicauda } \\
\text { antivenom } \\
\text { http://www.rshm.gov.tr/en/ }\end{array}$ & $\begin{array}{l}\text { Refik Saydam Hygiene Center, } \\
\text { Turkey }\end{array}$ & $\begin{array}{l}\text { Horse purified } \mathrm{F}(\mathrm{ab})_{2} \text {, } \\
\text { vial } 10 \mathrm{~mL} \text { (lyophilized), } \\
\text { neutralizes } 500 \mathrm{LD}_{50} / \mathrm{mL}\end{array}$ & $\begin{array}{l}\text { Androctonus } \\
\text { crassicauda }\end{array}$ \\
\hline
\end{tabular}

Note: *Accessed February 27, 2012.

requires immunotherapy in addition to administration of salicylates. The antivenom dosage depends on its neutralizing titer. Administration should be done via the intravenous route, either as a direct slow intravenous push in cases of severe envenoming (grade III) or by infusion in $250 \mathrm{~mL}$ of saline administered over 30 minutes. Immunotherapy might be repeated after two hours if cure is not obtained on the first attempt.

In cases of cardiac arrhythmia or hypertension, prazosin $(30 \mu \mathrm{g} / \mathrm{kg}$ orally every 6 hours for 48 hours or until clinical improvement) can be used, and in combination with immunotherapy, including in remote health centers. If cardiovascular complications are significant (acute pulmonary edema, heart failure, shock), it is necessary to use more specialized treatment, especially given that specific investigations will be needed (eg, electrocardiography, echocardiography). Dobutamine should be considered (infusion of $10 \mu \mathrm{g} / \mathrm{kg} /$ minute until normalization of left ventricular ejection fraction, then $5 \mu \mathrm{g} / \mathrm{kg}$ every 12 hours). Neuromuscular disorders (tremors, cramps, convulsions) may 
be treated with benzodiazepines, based on clinical signs and response to treatment, ie, midazolam $(0.05-0.2 \mathrm{mg} / \mathrm{kg}$ orally or intravenously) or diazepam $(0.5 \mathrm{mg} / \mathrm{kg}$ intravenously or rectally) every 12 hours.

\section{Conclusion}

Whatever the treatment, ie, antivenom or intensive care, it has been shown that mortality decreases wherever the management of scorpion stings has been anticipated and organized by health authorities. ${ }^{1}$ However, the choice between the two options requires realistic consideration of all relevant parameters, including logistics. In addition, mortality should not be the only endpoint; one should also consider the simplicity of management and rapidity of recovery. The complexity of contradictory clinical symptoms causes difficulty to choose symptomatic treatments, especially given that progression of symptoms and onset of complications may be rapid. While some drugs can be routinely used with a relevant and accurate protocol, many others remain the prerogative of the specialist. In contrast, treatment with antivenom, designed to eliminate venom from the organism rapidly, is likely to be the most logical and now easier to manage with low risks. Fragments of purified IgG are very effective and safe, even when administered by nonmedical personnel, provided that they have been trained. Administered early, they can prevent serious complications and reduce transfers to referral hospitals, but this strategy requires ready access to antivenom in remote health facilities.

In many cases, the combination of immunotherapy and symptomatic treatment remains a necessity. These treatment strategies potentiate each other, and give a satisfactory response to most common situations encountered in tropical countries. ${ }^{56}$ The training of health personnel regarding these combined treatment protocols should be extended to all countries where the incidence of scorpion stings is high. Public information on these new therapeutic strategies is essential in order to promote early presentation to health centers.

\section{Disclosure}

The author reports no conflicts of interest in this work.

\section{References}

1. Chippaux JP, Goyffon M. Epidemiology of scorpionism: a global appraisal. Acta Trop. 2008;107(2):71-79.

2. Celis A, Gaxiola-Robles R, Sevilla-Godinez E, de Orozco Valerio MJ, Armas J. Trends in mortality from scorpion stings in Mexico, 1979-2003. Rev Panam Salud Publica. 2007;21(6):373-380. Spanish.
3. Goyffon M, Vachon M, Broglio N. Epidemiological and clinical characteristics of the scorpion envenomation in Tunisia. Toxicon. 1982;20(1):337-344.

4. Soulaymani R, Faraj Z, Semlali I. Epidemiological aspects of scorpion stings in Morocco. Rev Epidemiol Santé Publ. 2002;50(4):341-347. French.

5. Soulaymani Bencheikh R, Faraj Z, Semlali I, Ouammi L, Badri M. National strategy in the battle against scorpion stings and envenomations. Application and evaluation. Bull Soc Pathol Exot. 2003;96(4):317-319. French.

6. Soulaymani Bencheikh R, Idrissi M, Tamim O, et al. Scorpion stings in one province of Morocco: epidemiological, clinical and prognosis aspects. J Venom Anim Toxins Incl Trop Dis. 2007;13(2):462-471.

7. Chippaux JP. Estimating the global burden of snakebite can help to improve management. PLoS Med. 2008;5(11):e221.

8. Tan PT, Veeramani A, Srinivasan KN, Ranganathan S, Brusic V. SCORPION2: a database for structure-function analysis of scorpion toxins. Toxicon. 2006;47(3):356-363.

9. Bosmans F, Tytgat J. Voltage-gated sodium channel modulation by scorpion a-toxins. Toxicon. 2007;49(2):142-158.

10. Possani LD, Becerril B, Delepierre M, Tytgat J. Scorpion toxins specific for $\mathrm{Na}^{+}$-channels. Eur J Biochem. 1999;264(2):287-300.

11. Rodríguez de la Vega RC, Possani LD. Overview of scorpion toxins specific for $\mathrm{Na}^{+}$channels and related peptides: biodiversity, structurefunction relationships and evolution. Toxicon. 2005;46(8):831-844.

12. Meves H, Simard JM, Watt DD. Interactions of scorpion toxins with the sodium channel. Ann NY Acad Sci. 1986;479(1):113-132.

13. Rodríguez de la Vega C, Possani LD. Novel paradigms on scorpion toxins that affect the activating mechanism of sodium channels. Toxicon. 2007;49(2):171-180.

14. Vasconcelos F, Lanchote VL, Bendhack LM, Giglio JR, Sampaio SV, Arantes EC. Effects of voltage-gated $\mathrm{Na}^{+}$channel toxins from Tityus serrulatus venom on rat arterial blood pressure and plasma catecholamines. Comp Biochem Physiol C Pharmacol Toxicol. 2005;141(1):85-92.

15. Rodríguez de la Vega RC, Possani LD. Current views on scorpion toxins specific for $\mathrm{K}^{+}$-channels. Toxicon. 2004;43(8):865-875.

16. Freire-Maia L, Campos JA. Pathophysiology and treatment of scorpion poisoning. In: Ownby CL, Odell GV, editors. Natural Toxins, Characterization, Pharmacology and Therapeutics. Proceedings of the 9th World Congress on Animal, Plant and Microbial Toxins. Oxford, UK: Pergamon Press; 1989.

17. Freire-Maia L, Campos JA, Amaral CF. Approaches to the treatment of scorpion envenoming. Toxicon. 1994;32(9):1009-1014.

18. Ismail M. The scorpion envenoming syndrome. Toxicon. 1995;33(7): 825-858.

19. Bahloul M, Ben Hamida C, Chtourou K, et al. Evidence of myocardial ischaemia in severe scorpion envenoming. Myocardial perfusion scintigraphy study. Intensive Care Med. 2004;30(3):461-467.

20. Benvenuti LA, Douetts KV, Cardoso JLC. Myocardial necrosis after envenoming by the scorpion Tityus serrulatus. Trans R Soc Trop Hyg. 2002;96(3):275-276

21. Daisley H, Alexander D, Pitt-Miller P. Acute myocarditis following Tityus trinitatis envenoming: morphological and pathophysiological characteristics. Toxicon. 1999;37(1):159-165.

22. Bahloul M, Chaari A, Dammak H, et al. Pulmonary edema following scorpion envenoming: Mechanisms, clinical manifestations, diagnosis and treatment. Int J Cardiol. 2012;158(2):292-293.

23. Sofer S, Gueron M, White R, Lifshitz M, Apte R. Interleukin-6 release following scorpion sting in children. Toxicon. 1996;34(3): 389-392.

24. Magalhães MM, Pereira ME, Amaral CFS, et al. Serum levels of cytokines in patients envenomed by Tityus serrulatus scorpion sting. Toxicon. 1999;37(8):1155-1164.

25. Meki AR, Mohey El-Dean ZM. Serum interleukin-1 $\beta$, interleukin-6, nitric oxide and a1-antitripsin in scorpion envenomed children. Toxicon. 1998;36(12):1851-1859. 
26. D’Suze G, Moncada S, González C, Sevcik C, Aguilar V, Alagón A. Relationship between plasmatic levels of various cytokines, tumour necrosis factor, enzymes, glucose and venom concentration following Tityus scorpion sting. Toxicon. 2003;41(3):367-375.

27. Abdel-Haleem AA, Meki AMA, Noaman HA, Mohamed ZT. Serum levels of IL- 6 and its soluble receptor, TNF- $\alpha$ and chemokine RANTES in scorpion envenomed children: their relation to scorpion envenomation outcome. Toxicon. 2006;47(4):437-444.

28. Adi-Bessalem S, Hammoudi-Triki D, Laraba-Djebari F. Pathophysiological effects of Androctonus australis hector scorpion venom: tissue damages and inflammatory response. Exp Toxicol Pathol. 2008;60(4-5):373-380.

29. Petricevich VL. Scorpion venom and the inflammatory response. Mediators Inflamm. 2010;903295.

30. Jalali A, Pipelzadeh MH, Taraz M, Khodadadi A, Makvandi M, Rowan EG. Serum TNF- $\alpha$ levels reflect the clinical severity of envenomation following a Hemiscorpius lepturus sting. Eur Cytokine Netw. 2011;22(1):5-10.

31. de Sousa Alves R, do Nascimento NR, Barbosa PS, et al. Renal effects and vascular reactivity induced by Tityus serrulatus venom. Toxicon. 2005;46(3):271-276.

32. Gmar-Bouraoui S, Ben Dhia N, Frih A, Skhiri H, Achour A, el May M. Scorpion sting and acute interstitial nephropathy: Apropos of 1 case. Méd Trop. 2000;60(3):305-306

33. Jain MK, Indurkar M, Kastwar V, Malviya S. Myocarditis and multiple cerebral and cerebellar infarction following scorpion sting. J Assoc Physicians India. 2006;54(6):491-492.

34. Romero NO, Hernández TJM. Cerebral edema associated to scorpion sting: a two-case sting report. J Venom Anim Toxins Incl Trop Dis. 2005;11(4):594-600.

35. Thacker AK, Lal R, Misra M. Scorpion bite and multiple cerebral infarcts. Neurol India. 2002;50(1):100-102.

36. Khattabi A, Soulaymani-Bencheikh R, Achour S, Salmi LR; for the Scorpion Consensus Expert Group. Classification of clinical consequences of scorpion stings: consensus development. Trans $R$ Soc Trop Med Hyg. 2011;105(7):364-369.

37. Arrowsmith JB, Kennedy DL, Kuritsky JN, Faich GA. National patterns of aspirin use and Reye syndrome reporting, United States, 1980 to 1985 . Pediatrics. $1987 ; 79(6): 858-863$.

38. Hall SM, Plaster PA, Glasgow JF, Hancock P. Preadmission antipyretics in Reye's syndrome. Arch Dis Child. 1988;63(7):857-866.

39. Ismail $M$. The treatment of the scorpion envenoming syndrome: the Saudi experience with serotherapy. Toxicon. 1994;32(9): 1019-1026.

40. Nascimento EB Jr, Costa KA, Bertollo CM, et al. Pharmacological investigation of the nociceptive response and edema induced by venom of the scorpion Tityus serrulatus. Toxicon. 2005;45(5):585-593.

41. Bawaskar HS, Bawaskar PH. Severe envenoming by the Indian red scorpion Mesobuthus tamulus: the use of prazosin therapy. QJM. 1996;89(9):701-704.
42. Bawaskar HS, Bawaskar PH. Vasodilators: scorpion envenoming and the heart (an Indian experience). Toxicon. 1994;32(9):1031-1040.

43. Krishnan A, Sonawane RV, Karnad DR. Captopril in the treatment of cardiovascular manifestations of Indian red scorpion (Mesobuthus tamulus concanesis Pocock) envenoming. J Assoc Physicans India. 2007;55(1):22-26

44. Gupta BD, Parakh M, Purohit A. Management of scorpion sting: prazosin or dobutamine. J Trop Pediatr. 2010;56(2):115-118.

45. Gibly R, Williams M, Walter FG, McNally J, Conroy C, Berg RA. Continuous intravenous midazolam infusion for Centruroides exilicauda scorpion envenoming. Ann Emerg Med. 1999;34(5):620-625.

46. Boyer LV, Theodorou AA, Berg RA, et al; Arizona Envenomation Investigators. Antivenom for critically ill children with neurotoxicity from scorpion stings. N Engl J Med. 2009;360(20):2090-2098.

47. Bawaskar HS, Bawaskar PH. Role of atropine in management of cardiovascular manifestations of scorpion envenoming in humans. J Trop Med Hyg. 1992;95(1):30-35.

48. Seifert SA. Atropine use in Centruroides scorpion envenoming contraindicated or not? J Toxicol Clin Toxicol. 2001;39(6):599-600.

49. Chippaux JP, Goyffon M. Venoms, antivenoms and immunotherapy. Toxicon. 1998;36(6):823-846.

50. Ghalim N, El-Hafny B, Sebti F, et al. Scorpion envenoming and serotherapy in Morocco. Am J Trop Med Hyg. 2000;62(2):277-283.

51. Hammoudi-Triki D, Ferquel E, Robbe-Vincent A, Bon C, Choumet V, Laraba-Djebari F. Epidemiological data, clinical admission gradation and biological quantification by ELISA of scorpion envenomings in Algeria: effect of immunotherapy. Trans $R$ Soc Trop Med Hyg. 2004;98(4):240-250.

52. Sevcik C, D’Suze G, Díaz P, et al. Modelling Tityus scorpion venom and antivenom pharmacokinetics. Evidence of active immunoglobulin G's F(ab')2 extrusion mechanism from blood to tissues. Toxicon. 2004;44(7):731-741.

53. Abroug F, Elatrous S, Nouira S, Haguiga H, Touzi N, Bouchoucha S. Serotherapy in scorpion envenomation: a randomised controlled trial. Lancet. 1999;354(9182):906-909.

54. Bawaskar HS, Bawaskar PH. Utility of scorpion antivenin vs prazosin in the management of severe Mesobuthus tamulus (Indian red scorpion) envenoming at rural setting. J Assoc Physicians India. 2007;55(1):14-21

55. Chippaux JP, Stock RP, Massougbodji A. Methodology of clinical studies dealing with the treatment of envenoming. Toxicon. 2010;55(7):1195-1212.

56. Bawaskar HS, Bawaskar PH. Efficacy and safety of scorpion antivenom plus prazosin compared with prazosin alone for venomous scorpion (Mesobuthus tamulus) sting: randomised open label clinical trial. Br Med J. 2011;342:c7136.
Drug Design, Development and Therapy

\section{Publish your work in this journal}

Drug Design, Development and Therapy is an international, peerreviewed open-access journal that spans the spectrum of drug design and development through to clinical applications. Clinical outcomes, patient safety, and programs for the development and effective, safe, and sustained use of medicines are a feature of the journal, which

\section{Dovepress}

has also been accepted for indexing on PubMed Central. The manuscript management system is completely online and includes a very quick and fair peer-review system, which is all easy to use. Visit http://www.dovepress.com/testimonials.php to read real quotes from published authors 